\title{
Relationship of precipitating antibodies to soluble cellular antigens and histologically defined renal lesions in systemic lupus erythematosus
}

\author{
PATRICK J. W. VENABLES, ${ }^{1}$ TUNG YI, ${ }^{1}$ DAVID F. WOODROW, ${ }^{2}$ \\ JILL MOSS, ${ }^{2}$ AND RAVINDER N. MAINI ${ }^{1}$ \\ From the ${ }^{1}$ Division of Clinical Immunology, Kennedy Institute of Rheumatology, 6 Bute Gardens, London \\ W6 7DW, and the ${ }^{2}$ Department of Experimental Pathology, Charing Cross Hospital Medical School, \\ Fulham Palace Road, London W6 8RF
}

SUMmARY Antibodies to nuclear ribonucleoprotein (nRNP), Sm, SS-A, and SS-B, were studied by a quantitative immunodiffusion technique in 48 patients with systemic lupus erythematosus (SLE). There was no correlation between the presence or titre of antibodies to any of these antigens and clinically apparent renal disease. However, among 34 patients who had renal biopsies antibodies to $\mathrm{nRNP}, \mathrm{Sm}$, and/or SS-A were seen in all 8 patients with membranous glomerulonephritis. Lowtitre antibodies (less than 1:4) were seen in 3 out of 7 patients with diffuse proliferative glomerulonephritis. Longitudinal studies in 4 patients who had serial biopsies indicated that the association between serological and histological findings was maintained for prolonged periods. In 2 patients whose biopsy pattern changed, antibodies to nRNP, Sm, and SS-A antedated the development of membranous nephritis.

Antibodies to the soluble cellular antigens nuclear ribonucleoprotein (nRNP), Sm, SS-A, and SS-B occur frequently in the sera of patients with systemic lupus erythematosus (SLE). With the exception of anti-Sm ${ }^{1}$ these antibodies are of limited diagnostic significance in SLE but may be important in defining 'clinical subsets,' particularly in relation to renal disease. It has been suggested that anti-nRNP and Sm are associated with relatively mild renal disease, ${ }^{23}$ and membranous nephritis commonly occurs in association with anti-Sm. ${ }^{3}$ Little information is available concerning associations between antibodies to SS-A or SS-B and patterns of renal involvement, though in one study anti-SS-A eluted from the kidneys of 2 patients with nephritis was thought to be of pathogenic importance. ${ }^{4}$

The purpose of this study was to identify and quantitate antibodies to nRNP, Sm, SS-A, and SS-B in patients with SLE and to compare the serological findings with functional and histological manifestations of renal disease in SLE. Serial serum samples were examined in 4 patients in whom serial biopsies were also available in order to ascertain Accepted for publication 13 January 1982. Correspondence to Dr P. J. W. Venables. whether the antibody profile could be used to predict the evolution of the renal lesion which ultimately developed.

\section{Material and methods}

Sera from 48 patients fulfilling 4 or more preliminary American Rheumatism Association (ARA) criteria for $\mathrm{SLE}^{5}$ were included in the study. In order to ensure a reasonably homogeneous population, patients with 'overlap syndromes' (many of whom fulfilled ARA criteria for SLE) were excluded if they fulfilled the criteria for 'mixed connective tissue disease' (MCTD) suggested by Bennett et al. ${ }^{6}$ Sera from 34 patients who had renal biopsies were taken at the time of biopsy.

The renal biopsies were processed for light microscopy, electronmicroscopy, and immunofluorescence as described previously. ${ }^{7}$ They were subdivided into 5 groups according to the scheme proposed by Appel et al. ${ }^{8}$ All the biopsies were reviewed by a single observer (DFW) without knowledge of the serological findings. The classification was as follows:

Class I. Normal kidneys. 
Class II. Mesangial changes (classes IIa and IIb were included as a single group in this study).

Class III. Focal and segmental proliferative nephritis.

Class IV. Diffuse proliferative nephritis.

Class $V$. Membranous glomerulonephritis.

In patients in whom more than one biopsy was available the serological and histological data presented in Figs. 2 and 3 corresponds to the biopsy taken at the time of the clinical onset of renal disease.

Rabbit thymus extract (RTE) was used as previously described ${ }^{9}$ as a source of nRNP and Sm, and a sonicated extract of Raji cells (RCE) as a source of SS-A and SS-B. The cells were prepared as for $\mathrm{Wil}_{2}$ cells, ${ }^{10}$ but in this study Raji cells were used in preference as they gave a better separation of SS-A and SS-B precipitins. $5 \mathrm{~mm}$ wells, containing $30 \mu \mathrm{l}$, were cut as hexagons $3 \mathrm{~mm}$ apart in $0.5 \%$ agarose in 0.15 M phosphate buffered saline (PBS), pH 7.2. Reference sera giving 2 known precipitins were placed in the top and bottom wells. An anti-nRNP and $\mathrm{Sm}$ reference serum was used at a fixed dilution of $1: 10$ with RTE, and an anti-SS-A/SS-B reference diluted 1:8 was used with RCE. Test sera were applied neat, and serially diluted $1: 4,1: 16$, and 1:64



Fig. 1 Immunodiffusion for the demonstration of antibodies to $n R N P$ and $S m$. A reference serum yielding 2 precipitins was placed in the top and bottom wells and the antigen rabbit thymus extract (RTE) in the centre well. The test serum is placed neat $(N)$ and serially diluted 1:4, 1:16, and 1:64 in the remaining wells. The nRNP precipitin (nearest the antigen well) is shown by a line of identity to be present to a titre of 1:64 in the test serum. The anti-Sm titre is $1: 4$. in the remaining 4 wells. The plates were left at $4^{\circ} \mathrm{C}$ for 4 days and read after immersion for 1 hour in $5 \%$ sodium citrate (Fig. 1).

Antibodies to double-stranded DNA were determined by the Farr assay with a standardised kit supplied by the Radiochemical Centre Amersham. ${ }^{11}$

Fisher's $\chi^{2}$ test was used to compare the frequency of antibodies detected in the histologically defined subgroups.

\section{Results}

The frequency of the different antibody systems and their associations are shown in Table 1 . It can be seen that $65 \%$ of the sera gave a precipitin reaction with one or more of the soluble cellular antigens nRNP, Sm, SS-A, and SS-B. Sixteen sera contained a defined single antibody specificity: 4 with anti-nRNP, one with anti-Sm, and 11 with anti-SS-A. In 15 sera 2 or more antibody systems were detected; 7 out of the 9 with anti-Sm also contained anti-nRNP and all 5 sera with anti-SS-B also contained anti-SS-A. The frequency of elevated anti-DNA antibodies $(>25 \mathrm{U} / \mathrm{ml})$ was similar in each serological subgroup ranging from $60 \%$ (anti-SS-B) to $77 \%$ (anti-Sm).

The presence of clinically apparent renal disease defined by a creatinine clearance of less than 60 $\mathrm{ml} / \mathrm{min}$, proteinuria of greater than $300 \mathrm{mg}$ per 24 hours, and/or cells or casts in the urine did not appear to correlate with any of the antibody systems examined. Furthermore no correlation was observed

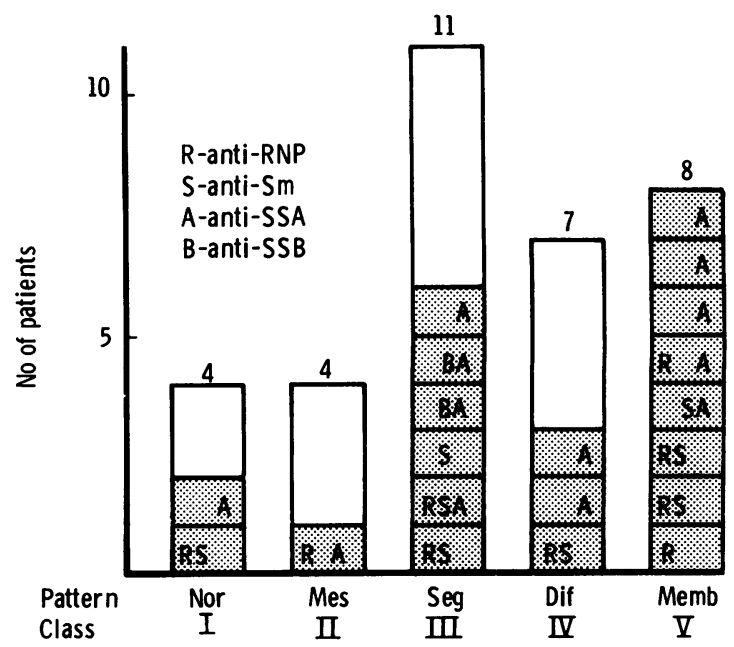

Fig. 2 Prevalence of antibodies to soluble cellular antigens in different renal histological patterns in SLE. The presence of detectable antibody is represented by a stippled area for each patient and its identity by a letter as shown in the key. 


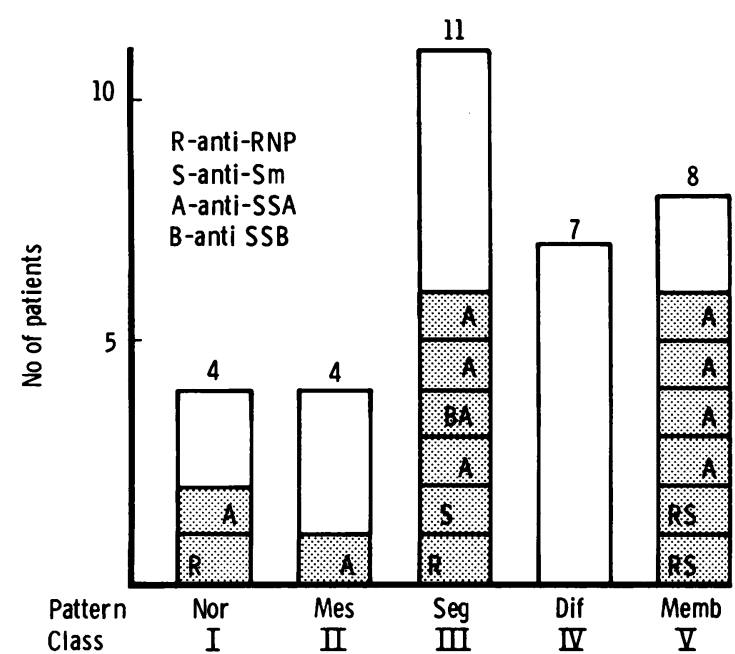

Fig. 3 Prevalence of antibodies to soluble cellular antigens with a titre of $1:<16$.

Table 1 Prevalence of precipitating antibodies to soluble cellular antigens

\begin{tabular}{|c|c|c|c|c|c|c|c|c|c|c|}
\hline & \multicolumn{2}{|c|}{ Anti-nRNP } & \multicolumn{2}{|c|}{ Anti-Sm } & \multicolumn{2}{|c|}{ Anti-SS-A } & \multicolumn{2}{|c|}{ Anti-SS-B } & \multicolumn{2}{|c|}{$\begin{array}{l}\text { Negative or } \\
\text { unidentified }\end{array}$} \\
\hline & No. & $\%$ & No. & $\%$ & No. & $\%$ & No. & $\%$ & No. & $\%$ \\
\hline \multirow{3}{*}{$\begin{array}{l}\text { Overall } \\
(n=48) \\
\text { Renal } \\
(n=32) \\
\text { 'Nonrenal } \\
(n=16)\end{array}$} & 13 & 27 & 9 & 19 & 20 & 42 & 5 & 10 & 17 & 35 \\
\hline & 8 & 25 & 7 & 21 & 12 & 37 & 2 & 6 & 13 & 40 \\
\hline & 5 & 31 & 2 & 12 & 8 & 50 & 3 & 18 & 4 & 25 \\
\hline
\end{tabular}

when each variable-for example, level of proteinuria, creatinine clearance-was analysed separately.

\section{RELATIONSHIP TO RENAL BIOPSY CHANGES}

Of 34 patients who underwent biopsies 4 were normal (class 1), 4 had mesangial changes (class II), 11 had a focal and segmental proliferative nephritis (class III), 7 diffuse proliferative nephritis (class IV), and 8 a membranous nephritis (class V). The most striking serological association was seen with the membranous lesion (Figs. 2, 3), all 8 patients having antibodies to one or more of the soluble cellular antigens: 5 had anti-SS-A, 3 anti-Sm, and 4 antinRNP. This is in contrast to the lower frequency found in the other groups $(\mathrm{p}<0 \cdot 05)$. If a higher titre $(>16)$ (Fig. 3) is taken as a cut-off point, 6 of the 8 with a membranous lesion were still positive and none of those with a diffuse lesion $(p=>0 \cdot 01)$.

Antibody titres, and their association with histological changes in serial biopsies, are shown in Fig. 4-6. Patient number 1, who had a persistent membranous lesion in 2 biopsies and at post mortem, had correspondingly high titres of anti-nRNP/Sm dating back to sera stored from 1971. Patient number 2, initially with a focal and segmental nephritis associated with high levels of DNA binding and antibodies to SS-A, nRNP, and Sm, showed a fall in titre of all 4 antibody systems following treatment with cyclophosphamide. A follow-up biopsy in 1980 showed that she had subsequently developed a membranous nephropathy. Patient number 3 , who presented with a mild mesangial lesion in 1975 , developed a mem-

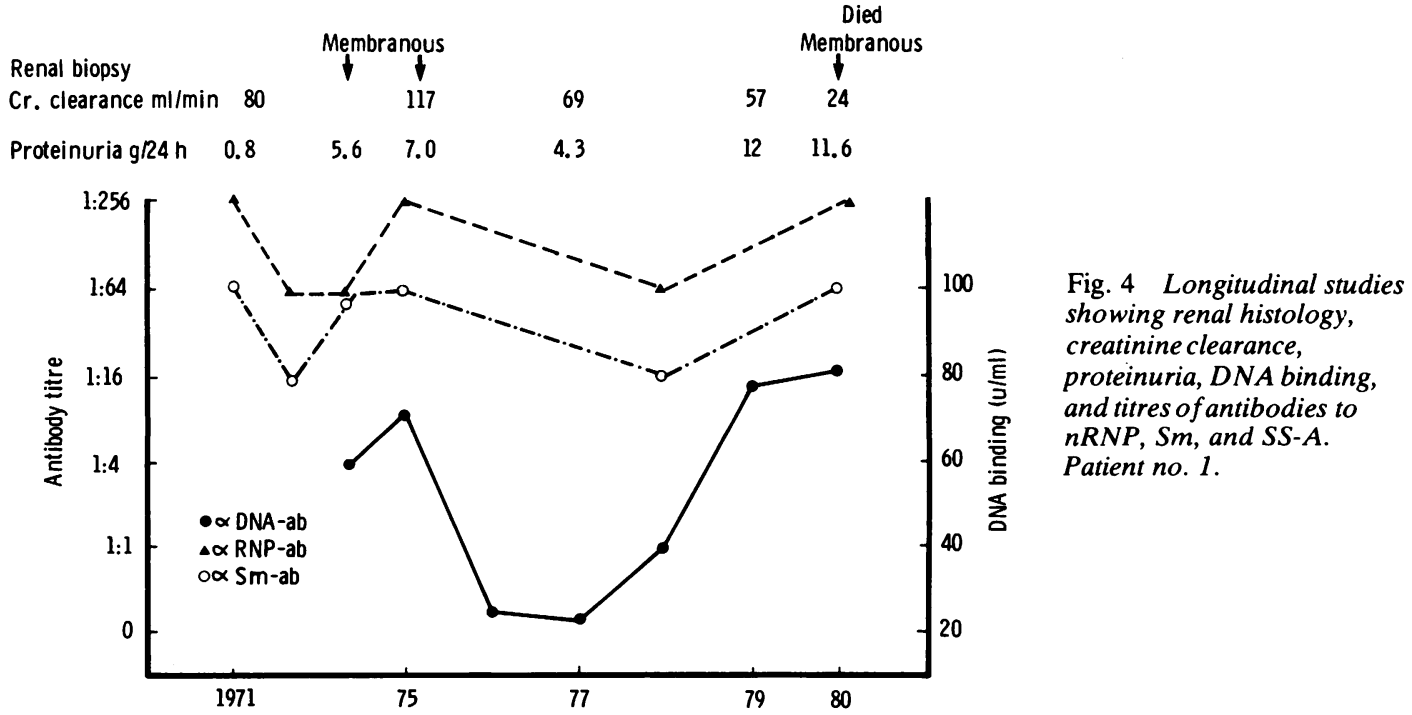

Fig. 4 Longitudinal studies creatinine clearance, antibodies to $n R N P, S m$, and $S S-A$ Patient no. 1. 


$\begin{array}{lcc}\text { Renal biopsy } & \text { Segmental } & \text { Membranous } \\ \text { Cr clearance } \mathrm{ml} / \mathrm{min} & 57 & 47 \\ \text { Proteinuria g/24 h } & 1.5 & 5.0\end{array}$


Fig. 6 Longitudinal studies showing renal histology, creatinine clearance, proteinuria, DNA binding, and titres of antibodies to $n R N P, S m$, and SS-A. Patient no. 3.

branous nephritis with heavy proteinuria a year later. It is of interest that high-titre anti-nRNP/Sm was present throughout her illness and preceded the onset of the membranous lesion by at least 1 year. A fourth patient (data not shown in Figures) had a diffuse proliferative nephritis demonstrated on serial biopsies over a 5-year period. Serial sera showed elevated levels of DNA binding but a persistently low titre (less than 1:4) of anti-nRNP and Sm over the same period.

\section{Discussion}

Our study has shown a high prevalence of antibodies to soluble cellular antigens in SLE, a positive association with membranous glomerulonephritis, and a negative relationship to diffuse proliferative glomerulonephritis defined by strict histological criteria on renal biopsy.

The frequency of the different antibody systems in this study is similar to that of previous reports ${ }^{1213}$ 
except for a relatively low frequency of anti-Sm $(19 \%)$. This may be due to case selection, drug therapy, and race, ${ }^{13}$ and also to the sensitivity of the assays. The haemagglutination (HA) test, which is probably more sensitive than immunodiffusion for detecting anti-Sm, has been widely used in other surveys. ${ }^{31214}$ However, it is now becoming apparent that antibodies to antigens other than Sm may account for high HA titres in some sera. ${ }^{15}$ Counterimmunoelectropheresis, though more sensitive for the detection of antibodies to some protein antigens, ${ }^{9}$ has been found to be less sensitive than immunodiffusion for anti-Sm. ${ }^{15}$ For this reason the analyses in this study are based entirely on immunodiffusion. Also noteworthy is the high prevalence of antibodies to SS-A (42\%). Although at variance with previous reports, ${ }^{16}$ this finding has been supported by a more recent study ${ }^{13}$ and by the observation that the Ro system, now known to be immunologically identical to SS-A, ${ }^{17}$ also reacts commonly with SLE sera. ${ }^{18}$ In this study SS-A precipitins were relatively weak and were sometimes obscured by other precipitins at low dilutions but became easily identified at a titre of $1: 16$ or $1: 64$. This observation emphasises the importance of testing every serum at a range of dilutions, particularly with SLE sera when a number of different antibodies may be present.

Our study has failed to confirm a low frequency of renal disease previously reported to be associated with anti-nRNP ${ }^{2}$ and anti-Sm. ${ }^{3}$ Our negative findings, which are in agreement with those of some studies, ${ }^{19}$ are probably due to the selection of patients on clinical rather than serological criteria, and the exclusion of overlap syndromes with MCTD-like features. This has resulted in the finding of 'pure' antinRNP (i.e., in the absence of anti-DNA, Sm, or SS-A) in only 2 patients and none with 'pure' anti$\mathrm{Sm}$. Thus our study is not comparable with those in which patients were selected on the basis of defined serological subgroups. ${ }^{23}$

The main positive finding in this study was the presence of antibodies to SS-A, nRNP, and/or Sm in the sera of all 8 patients with membranous nephritis. In contrast only 3 of the patients with a proliferative lesion had these antibodies, and with a relatively low titre (less than 1:4). The serial studies confirm these associations over prolonged periods (in one case 9 years), and suggest that antibodies to nRNP, Sm, and SS-A may occur in the serum before the development of a membranous lesion. Our findings are supported by those of Winn et al., ${ }^{3}$ who, using a semipurified $\mathrm{Sm}$ antigen in an HA test, showed a high frequency of membranous nephritis and a low frequency of proliferative glomerulonephritis in SLE patients whose sera contained anti-Sm.

Our finding of an association of anti-SS-A with membranous nephritis has not been previously described, though a reason for a negative correlation with a proliferative lesion is suggested by one study ${ }^{4}$ : in 2 patients with anti-Ro (SS-A) the rapid development of proliferative glomerulonephritis was associated with a fall in anti-Ro titres and the recovery of anti-Ro from kidney eluates. This, in combination with our findings, suggests that the absence of these antibodies in the sera of patients with proliferative glomerulonephritis could be due to their specific concentration, in complexed form, in the kidney. However, our findings suggest that if this mechanism is important it may also apply to antibodies to nRNP and $\mathrm{Sm}$.

Another explanation suggested by Winn et al. ${ }^{3}$ is based on the possibility that the Sm antigen may inhibit the formation of DNA anti-DNA complexes. ${ }^{20}$ It is possible that the other soluble cellular antigens, which are also negatively charged and have a relatively narrow range of molecular weights (50 000-200 000 Daltons), may have a similar relationship to DNA. A third mechanism might concern the size of immune complexes, particularly in relation to membranous nephritis. However, until the soluble cellular antigens are demonstrated in renal deposits from SLE patients these explanations remain speculative. Nevertheless the correlative findings in our study suggest a possible role for antibodies to the soluble cellular antigens in some types of SLE nephritis.

We thank Dr J. T. Scott for allowing us to include some of his patients in this study and the Arthritis and Rheumatism Council for their continuing support.

Dr Tung Yi was supported by a WHO scholarship and an award from the Henry Lestor trust.

\section{References}

1 Tan E M, Kunkle H G. Characteristics of a soluble nuclear antigen precipitating with sera of patients with systemic lupus erythematosus. J Immunol 1966; 96: 464-71.

2 Reichlin M, Mattioli M. Correlation of a precipitin reaction to an RNA protein and a low prevalence of nephritis in patients with systemic lupus erythematosus. N Engl J Med 1972; 286: 908-11.

3 Winn D M, Wolfe J F, Lindberg D A, Fristoe F H, Kingsland L, Sharp G C. Identification of a clinical subset of systemic lupus erythematosus by antibodies to the Sm antigen. Arthritis Rheum 1979; 22: 1334-7.

4 Maddison P J, Reichlin M. Deposition of antibodies to a soluble cytoplasmic antigen in the kidneys of patients with systemic lupus erythematosus. Arthritis Rheum 1979; 22: 858-63.

5 American Rheumatism Association criteria for diagnosis and classification of rheumatic diseases. Primer on Rheumatic Diseases. JAMA 1973; 224: (suppl) 137-8.

6 Bennett $\mathrm{R} \mathrm{M}$, O'connell $\mathrm{D} \mathrm{J}$. The arthritis of mixed connective tissue disease. Ann Rheum Dis 1978; 37: 397-403.

7 Rainford D J, Woodrow D F, Sloper J C, de Wardener H E, Griffith I. Post meningococcal acute glomerulonephritis. Clin Nephrol 1978; 9: 249-53. 
8 Appel G B, Silva F G, Pirani C L, Meltzer J I, Estes C. Renal involvement in systemic lupus erythematosus (SLE). Medicine 1978; 57: 371-7.

9 Venables P J W, Erhardt C C, Maini R N. Antibodies to extractable nuclear antigens in rheumatoid arthritis: relationship to vasculitis and circulating immune complexes. Clin Exp Immunol 1980; 39: 146-53.

10 Venables P J W, Roffe L M, Erhardt C C, Edwards J M B, Porter A D, Maini R N. Titres of antibodies to RANA in rheumatoid arthritis and normal sera: relationship to Epstein-Barr virus infection. Arthritis Rheum 1981; 24: 1459-65.

11 Griffiths I D, Holian J, Maini R N. Measurement of anti-DNA antibodies: report on the organisation and results of an Arthritis and Rheumatism Council Workshop Study. Ann Rheum Dis 1976; 36 suppl: 67-75.

12 Notman D D, Kurata N, Tan E M. Profiles of antinuclear antibodies in rheumatic diseases. Ann Intern Med 1975; 83: 464-9.

13 Scopelitis E, Biundo J R, Alspaugh M A. Anti-SS-A antibody and other antinuclear antibodies in systemic lupus erythematosus. Arthritis Rheum 1980; 23: 287-93.
14 Reinitz E, Grayzel A, Barland P. Specificity of Sm antibody. Arthritis Rheum 1980; 23: 869.

15 Tung Y, Venables P J W, Maini R N. The polyclonality of antibodies to soluble cellular antigens in SLE: evaluation of 3 screening tests. Ann Rheum Dis 1981; 40: 520.

16 Alspaugh M A, Talal N, Tan E M. Differentiation and characterisation of auto-antibodies and their antigens in Sjögren's syndrome. Arthritis Rheum 1976; 19: 216-22.

17 Alspaugh M A, Maddison P J. Resolution of the identity of certain antigen-antibody systems in systemic lupus erythematosus and Sjögrens syndrome. Arthritis Rheum 1979; 22: 796-8.

18 Clark G, Reichlin M, Tomasi T B. Characterisation of a soluble cytoplasmic antigen reactive with sera from patients with systemic lupus erythematosus. J Immunol 1968; 102; 117-22.

19 Hochberg M C, Dorsch C A, Feinglass E J, Stephens M B. Survivorship in systemic lupus erythematosus. Arthritis Rheum 1981; 24: 54-9.

20 Reyes P A, Tan E M. DNA binding property of Sm nuclear antigen. $J$ Exp Med 1977; 145: 749-54. 